\title{
İyonize Radyasyon ile Çalışan Tıbbi Görüntüleme Cihazlarının Yapısının Proje Temelli Öğrenimi
}

\author{
Project Based Learning of the Structure of Medical Imaging Devices Working with \\ Lonizing Radiation
}

\section{Osman GÜNAY' ${ }^{\mathbb{D}}$, Hilal ÖZTÜRK ${ }^{1}$ (D) Onur YARAR ${ }^{1}$}

öz

Tıbbi görüntüleme yöntemlerinden bazılarında x-1şınları ve gama 1şınları kullanılmaktadır. Tıbbi görüntüleme cihazları, Üniversitelerin Sağlı Hizmetleri Meslek Yüksekokulları bünyesinde bulunan Tıbbi Görüntüleme Teknikleri Programından mezun olan Tıbbi Görüntüleme Teknikerleri tarafindan kullanılmaktadır. Mezunların mesleki başarılarında aldıkları eğitim yöntemi oldukça önemlidir. Bu yöntemlerin bir tanesi de proje temelli öğrenme yöntemidir.

$\mathrm{Bu}$ çalışma, Tıbbi Görüntüleme Teknikleri Programı öğrencilerinin tıbbi görüntüleme cihazlarının yapısını ve çalışma prensiplerini daha iyi öğrenebilmesi amacıyla yapılmıştır. Bu amaç için, öğrenciler farklı gruplara ayrılmıştır. Her grup, röntgen, bilgisayarlı tomografi, mamografi, tek foton emisyon bilgisayarlı tomografi (SPECT) ve pozitron emisyon tomografisi (PET) cihazlarından birini seçmişlerdir. Her grup seçtikleri görüntüleme cihazının yapısı ve çalışma prensipleri ile ilgili yaptıkları literatür taraması sonucunda ve seçtikleri cihazın çeşitli materyaller kullanarak maket tasarımı yapmışlardır. Çalışma sonunda bütün gruplara cihazlarla ilgili sorulmuş ve öğrencilerin sorulara verdikleri cevaplar değerlendirilmiştir. Öğrenciler, yaptıkları cihazlarla ilgili olan sorulardan, diğer cihazlarla ilgili olan sorulara göre daha başarılı oldukları gözlenmiştir.

Anahtar Kelimeler: Radyasyon, T1bbi Görüntüleme, Eğitim

Osman GÜNAY (更), Hilal ÖZTÜRK, Onur YARAR

I'Istanbul Okan Üniversitesi Sağllk Hizmetleri Meslek Yüksekokulu ISTANBUL

e-posta: osman.gunay@okan.edu.tr

\begin{abstract}
$\mathrm{X}$-rays and gamma rays are used in some of the medical imaging methods. Medical imaging devices are used by medical imaging technicians who have graduated from the medical imaging techniques program within the health services vocational colleges of the universities. The education method of graduates is very important in their professional success. One of these methods is project-based learning.

This study was carried out in order to provide medical imaging techniques program students with a better understanding of the structure and working principles of medical imaging devices. For this purpose, students are divided into different groups. Each group chose X-ray, computed tomography, mammography, single photon emission computed tomography (SPECT) and positron emission tomography (PET). Each group searched the literature about the structure and working principles of the imaging device of their choice and designed a model using various materials. At the end of the study, all groups were asked about the devices and the answers of the students to the questions were evaluated. It was observed that the students were more successful than the questions about the devices they made, compared to the questions about the other devices.
\end{abstract}

Keywords: Radiation, Medical Imaging, Education

\section{GíRiş}

Teknolojinin ilerlemesiyle beraber günümüzde tıbbi görüntüleme cihazları da oldukça gelişmiştir. Tıbbi görüntüleme yöntemleri birçok şekilde sınıflandırılabilir. $\mathrm{Bu}$ sinıflandırma iyonize radyasyon kullanılarak yapılan ve iyonize radyasyon kullanılmadan yapılan görüntüleme yöntemleri şeklinde olabilir. İyonize radyasyon kullanılarak yapılan görüntüleme yöntemlerinde kullanılan cihazlarından bazıları, röntgen cihazı, bilgisayarlı tomografi (BT), mamografi, pozitron emisyon tomografisi (PET) ve tek foton emisyon bilgisayarlı tomografidir (SPECT). Bu cihazlardan, röntgen, bilgisayarlı tomografi ve mamografi cihazlarında x-1şını ışınları kullanılarak görüntüleme yapılmaktadır. 
PET ve SPECT cihazlarında ise gama ışınları kullanılarak görüntü elde edilmektedir. Bu cihazların kullanılmasından ve sonuçların değerlendirilmesinden birinci dereceden sorumlu kişiler tıpta uzmanlığını tamamlamış, radyoloji uzmanları veya nükleer tıp uzmanlarıdır. Bu uzmanlara yardımcı olan personeller ise, üniversitelerin ön lisans programından mezun olan, tıbbi görüntüleme teknikerleri ve nükleer tıp teknikerleridir (1-4).

İyonize radyasyonun kullanıldığ departmanlarında çalışan personelin sorumlulukları manyetik rezonans gibi iyonize radyasyon kullanılmayan tıbbi görüntüleme cihazlarında çalışan personele oranla çok daha fazladır. İyonize radyasyon kullanılan görüntüleme yöntemleri sırasında hasta, hasta yakını ve çalışan personelin gereksiz ve/veya yüksek radyasyon maruziyetine bağlı oluşabilecek erken, geç ve kalıtımsal etkilerin önlenmesi açısından bu cihazları kullanacak kişilere verilecek eğitim kalitesi oldukça önem kazanmaktadır.

Türkiye'de ön lisans eğitimi iki yıllık bir süreci kapsamaktadır. $\mathrm{Bu}$ eğitimler genellikle teorik olarak verilmektedir. Uygulamalı eğitim süresi ise oldukça sınırlıdır. Öğrenciler tıbbi görüntülemede kullanılan cihazların içyapılarını ve çalışma prensiplerini tam olarak öğrenememektedirler. Öğrencilerin tıbbi görüntüleme cihazlarının içyapılarını, çalışma ve görüntüleme prensiplerini, görüntüleme için kullanılan ışınların nasıl elde edildiğini, hangi aşamalardan geçtiğini, nereye ulaştığını ve görüntülerin nasıl oluşturulduğunu kavramaları gerekir. $\mathrm{Bu}$ bilgilerin tam öğrenilmesi; mezunların iş hayatına atıldıklarında çalıştıkları departmandaki cihazlara olan hâkimiyetlerini arttırarak mesleklerini tam ve yeterli olarak icra etmelerini sağlayacaktır.

Eğitim öğretimin, kişiye göre değişen birçok yöntemi vardır. $\mathrm{Bu}$ yöntemlerden en önemlilerden bir tanesi proje temelli öğrenmedir. Bu çalışmanın temel amacı, öğrencilerin iyonize radyasyon içeren tıbbi görüntüleme cihazlarından bazılarının iç ve dış yapısını cihazların maketlerini yaparak öğrenmesini sağlamaktır. Bunun için öğrenciler ilgi alanlarına göre farklı gruplara ayrılmıştır. Her grup, bir tane iyonize radyasyonun kullanıldığ 1 tıbbi görüntüleme cihazı seçmiştir. Seçtikleri bu cihazın maketini farklı materyaller kullanarak yapmışlardır.

Proje temelli öğrenmede, öğrenciler seçilmiş olan problemin üzerinde ve çevresinde çalışırlar. Problemin çözümünde ise diğer bilimsel disiplinlerden yararlanırlar. Birçok bilgi ve birikimi birleştirdiklerinden dolayı çalışma sonucunda meydana gelen ürün, sistematik bir araştırmanın süreci olarak görülmektedir $(5,6)$. Proje temelli öğrenmede, öğrenciler ve araştırmacılar, önce araştırma, sonra planlama, tasarlama ve sonunda da düşünme firsatı yakalamaktadırlar (7). Proje temelli öğrenmede, öğrenciler ve araştırmacılar, problemleri tamamen kendileri çözer. Konuyla ilgili gerekli bilgileri kendileri öğrendiklerinden dolayı proje temelli öğrenme oldukça etkilidir. Proje temelli öğrenme yönteminin oldukça fazla olumlu yönleri vardır. Proje temelli öğrenme, akademik başarıyı (8), araştırma becerilerini (9), akademik risk almayı, problem çözme becerisini (10), anlamlı öğrenmeyi (11), mantıksal düşünmeyi (12), bilimsel süreç becerilerini (13), olumlu yönde etkilediği ve kavram yanılgılarının azalmasını sağladığı çeşitli çalışmalarca belirlenmiştir.

$\mathrm{Bu}$ çalışmanın amacı, proje temelli öğrenme metodu aracılığıyla öğrencilerin iyonize radyasyon kullanılarak görüntüleme yapan röntgen cihazı, bilgisayarlı tomografi, mamografi, SPECT ve PET cihazlarının iç ve dış yapılarını ve çalışma prensiplerini öğrenmelerini sağlamaktır.

\section{GEREÇ VE YÖNTEM}

\section{Röntgen}

Geleneksel röntgen cihazı, X-1şını kullanarak görüntülemenin meydana getirildiği en temel ve en eski cihazdır. X-1̧̧ınlarının tanısal radyolojide kullanılmalarını sağlayan temel özelliği, dokuyu geçebilme yetenekleridir. Floresans ve fotografik özellikleri ise görüntünün elde edilmesini sağlar. İnsan vücudunun değişik atom ağırlığında ve değişik kalınlık ve yoğunlukta dokulardan oluştuğundan, $\mathrm{x}$-1şınının absorbsiyonu da farklı olacaktır. Farklı absorbsiyon ve girginlik sonucu, röntgen filmi (röntgenogram) üzerine değişik oranlarda düşen $\mathrm{x}$-1şını işınları geçtikleri vücut parçasının bir görüntüsünü oluştururlar. $\mathrm{Bu}$ görüntü, siyahtan (film üzerine düşen ışın fazla) beyaza (film üzerine düşen 1şın az) kadar değişen gri tonlardan oluşur.

Röntgen cihazlarında, farklı sürelerde, farklı kalitede ve miktarda X-1şını elde edilebilir. Üretilecek ve sistemde kullanılacak x-1şını miktarını, inceleme yapılacak organ veya vücut bölgesine göre belirlenir.

Röntgen cihazları, genel olarak radyografi ve radyoskopi cihazları olmak üzere iki gruba ayrılır. Radyografi cihazlarında statik bir görüntüleme yapılırken, radyoskopi cihazlarında dinamik bir görüntüleme yapılabilmektedir. Radyografi, bilgisayar teknolojisi ile birleştirilerek dijital 
röntgen cihazları üretilmiştir. Dijital röntgende, hastayı geçen X-1şınları, özel görüntü alıcı düzenek üzerine düşürülmektedir. Bu sistemde görüntüyü meydana getirecek olan veriler önce sayısal verilere dönüştürülür. Daha sonra bu sayısal verilerden ekran üzerinde görüntü elde edilir.

\section{Bilgisayarlı Tomografi (BT)}

Bilgisayarlı tomografi (BT) ile yapılan görüntülemede geleneksel röntgen görüntülemesindeki gibi $\mathrm{x}$-ışınları kullanılmaktadır. Bilgisayarlı tomografide, cihazın hareketli kısmının (gantri) içerisinde $\mathrm{X}$-1şını tüp ve tüpün tam karşısında dedektörler bulunur. X-1şını tüpünden üretilen, 1şınlar hasta vücudunu geçerken bir kısmı absorbe olurken bir kısmı vücuttan geçer. Vücuttan geçen kısımlar tüpün karşısındaki dedektörler tarafından algılanır ve sayısal verilere çevrilir. $\mathrm{Bu}$ sayısal veriler bilgisayar vasıtasıyla kesitsel görüntüye çevrilir.

BT cihazının, teorik temelleri 1967 ile 1971 yılları arasında oluşturulmuş ve 1972 yılında tıp alanına girmiştir. Y1llar içerisinde bilgisayarlı tomografi cihazlarındaki gelişmelere paralel olarak görüntüleme süresi kısalmış ve hastanın maruz kaldığı radyasyon dozu azalmıştır. İlk zamanlardaki cihazlarda görüntüleme süresi 5-6 dakika iken günümüzde bu süre saniyeler mertebesindedir.

Geleneksel röntgen cihazlarında 2 boyutlu görüntü elde edilebilmektedir. Fakat vücudun derinliklerindeki görüntülerin oluşturulması, hastalıkların teşhisi için oldukça önemlidir. Bu sebeple üç boyutlu görüntü elde edilmeye yönelik cihazlar geliştirilmeye çalışılmıştır.

BT cihazı geleneksel röntgen cihazlarına kıyasla oldukça gelişmiş bir tıbbi görüntüleme cihazıdır. Geleneksel görüntüleme elde edilemeyen bazı görüntüler özellikle yumuşak dokular, BT ile görüntülenebilmektedir. Röntgen cihazında organların görüntüleri üst üste gelirken, BT de kesitsel görüntüleme ile her bir organın, her bir dokusu rahatlıkla ayırt edilebilmektedir (14-18).

\section{Mamografi}

Mamografik görüntülemede, atom numaraları ve yoğunlukları birbirlerine oldukça yakın olan, yağ, glandüler ve kas dokuları incelenmektedir. Bu dokuların en önemli özelliği ise yumuşak doku olmasıdır. Günümüzde yüksek görüntüleme teknolojisine sahip birçok yöntem olsa da meme kanserinin erken tanısında en başarılı yöntem mamografidir. Mamografi, geleneksel röntgen incelemelerine göre bir takım farklılıklar taşımaktadır. Bunlardan en önemlileri, mamografide yumuşak doku incelendiği için, uygulanan gerilim 25 ile $50 \mathrm{kV}$ arasındadır.

\section{Tek Foton Emisyon Bilgisayarlı Tomografi (SPECT)}

SPECT görüntüleme sisteminin temelini oluşturan gama kameralarının sağlık sektöründe kullanılması 1960'lı yıllara dayanmaktadır. Fakat o yıllarda sadece iki boyutlu görüntü oluşturulabiliyordu. Teknolojinin gelişmesiyle birlikte, 1970'li yılların sonuna doğru ilk SPECT cihazları klinikte kullanılmaya başlanmıştır. İlk oluşturulan cihazlar, tek dedektörlü, daha sonra iki ve üç dedektörlü cihazlar geliştirilmiştir. İlk zamanlardaki SPECT in dedektörleri dairesel olarak tasarlanmıştı. $\mathrm{Bu}$ tasarımda organların bazı bölgeleri görüntü dışında kalmaktaydı. Daha sonra dikdörtgen şeklinde tasarlandı ve tüm vücut görüntülemeye uygun hale getirildi.

SPECT görüntülemeden önce hastaya gama 1şını yayan radyofarmasötik ajan verilmektedir. Hastaya verilen radyofarmasötik ajanın hedef organ ya da organlarda tutulması sonucunda, hastadan yayılan gama ışınları hasta etrafinda belli açı ve sürelerde dönen dedektörler tarafindan algılanır. Böylece gama ışınları sayısal veri haline getirilir. SPECT in en yaygın kullanıldığı nükleer tıp uygulamaları beyin, kalp ve kemik sintigrafisidir $(19,20)$.

\section{Pozitron Emisyon Tomografisi}

Pozitron emisyon tomografisi (PET); vücuttaki farklı organlarda bulunan fonksiyonel bozuklukları belirleyen, nükleer tıp görüntüleme yöntemidir. PET'de öncelikle hastanın vücuduna radyofarmasötik ajan enjekte edilir. $\mathrm{Bu}$ radyofarmasötik ajandan yayılan pozitronlar, serbest elektronlarla çarpışarak yok olma (annihilasyon) olayı ile zit yönlerde hareket eden $511 \mathrm{keV}$ enerjili 2 foton yayınlarlar. Yayınlanan bu fotonların dedektörler tarafından eş zamanlı algılanması sonucu görüntü elde edilir. PET ile dokulardan saçılan fotonların üç boyutlu, kesitsel görüntüleri elde edilir ve kanser odağının yeri tam olarak belirlenmiş olur (21-23).

\section{Araştırma Süreci}

Bu çalışma İstanbul Okan üniversitesi Tıbbi Görüntüleme Teknikleri Programı 2. sınıföğrencileri ile yapıldı. Öğrenciler, mezuniyet projesi kapsamında 5 farklı gruba ayrıldı. Her grupta rastgele belirlenen 6 ögrenci olup, öğrenciler ilgilerine göre belirlenen 5 cihazdan (Röntgen, Bilgisayarlı Tomografi, 
Mamografi, PET ve SPECT) bir tanesini seçtiler. Çalışma kapsamında öğrencilerden, seçtikleri görüntüleme cihazıyla ilgili teorik bilgi araştırması yapılması istendi. Öğrencilerin teorik bilgi araştırması sonunda hazırladıkları içerikler kaynaklarıyla birlikte kontrol edildi. Seçtikleri cihaz ile ilgili araştırmaları onaylanan öğrencilerden cihaz ile ilgili maket tasarımı yapmaları istendi. Öğrencilere maket yapımında kullanacakları materyalle ilgili herhangi bir sinırlandırılma yapılmadı. Aşamaları başarı ile tamamlayan öğrencilere maketlerini tamamlamaları için 2 haftalık süreç verildi. Son aşama olarak hazırladıkları maketler ve konu kapsamında oluşturdukları powerpoint dosyaları ile birlikte sunumları dinlenildi. Çalışmalarını tamamlamış ve sunumlarını gerçekleştirmiş tüm gruplara, içeriği 5 farklı cihazın yapısı ve çalışma prensipleri ile ilgili sözlü sınav yapılmıştır. Her cihaz için sorulan sorular eşit puan ağırlıklıdır. Öğrencilerin sorulara verdikleri yanıtlar öğretim üyeleri tarafindan değerlendirildi. Sonuçların istatistiksel analizleri yapıldı.

\section{BULGULAR VE TARTIŞMA}

Röntgen cihazı, hem yatar pozisyonlar için hasta yatakl1, (Şekil 1) hem de ayakta çekimler için statifli (Şekil 2) olarak, 1. grup öğrencileri tarafından yapılmıştır. X-1şını tüpü, hasta yatağı ve kaset tutucusu model üzerinde de açık bir şekilde gösterilmiştir. Hem yatak hem de kaset tutucu hareketli olarak tasarlanmıştır. Merkezi ışın göstergesi, basit bir elektrik devre düzeneğiyle oluşturulmuştur.

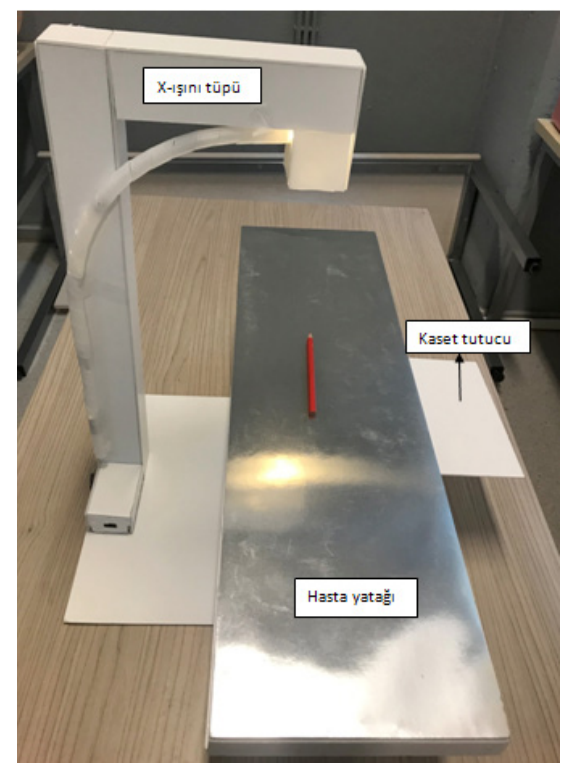

Şekil 1: Röntgen Cihazı (yataklı)
BT cihazı 2. grup öğrenciler tarafından tasarlanmıştır. Bilgisayarlı tomografi cihazi, kontrol odasiyla beraber tek bir platform üzerinde kurulmuştur. Cihazın yatak bölümü bir elektrik motoruyla hareket edebilmektedir. Elektrik motorunun kontrolü de kontrol paneli üzerindeki düğmelerle yapılmaktadır (Şekil 3). Şekil 4 de bilgisayarlı tomografi cihazının iç yapısı gösterilmiştir. Burada dişli sistemi kullanılarak $\mathrm{x}$-1şını tüpü ve dedektörlerin dönmesi sağlanmıştır. Dişliler, elektrik motoru vasıtasıyla dönebilmektedir. X-1şını tüpü ve dedektörler karşılıklı olarak dizili çarklar üzerine yerleştirilmiştir. Bu yapısıyla, günümüzde en çok kullanılan 3. jenerasyon BT cihazı sembolize edilmiştir.

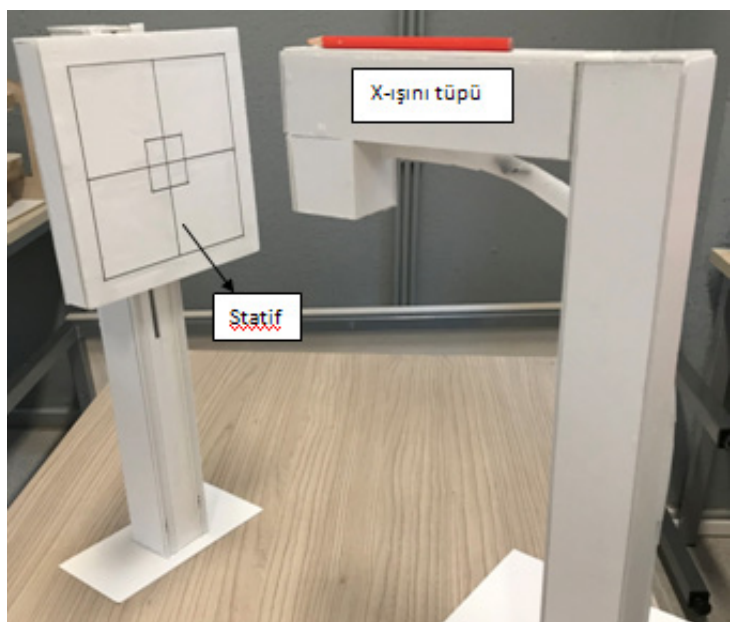

Şekil 2: Röngen Cihazı (ayakta çekim)

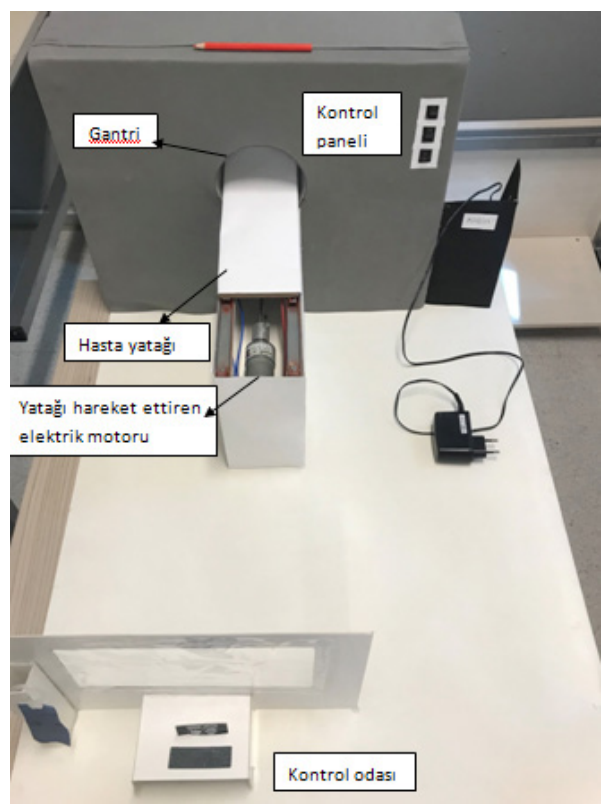

Şekil 3: Bilgisayarlı Tomografi (Önden Görünüş) 


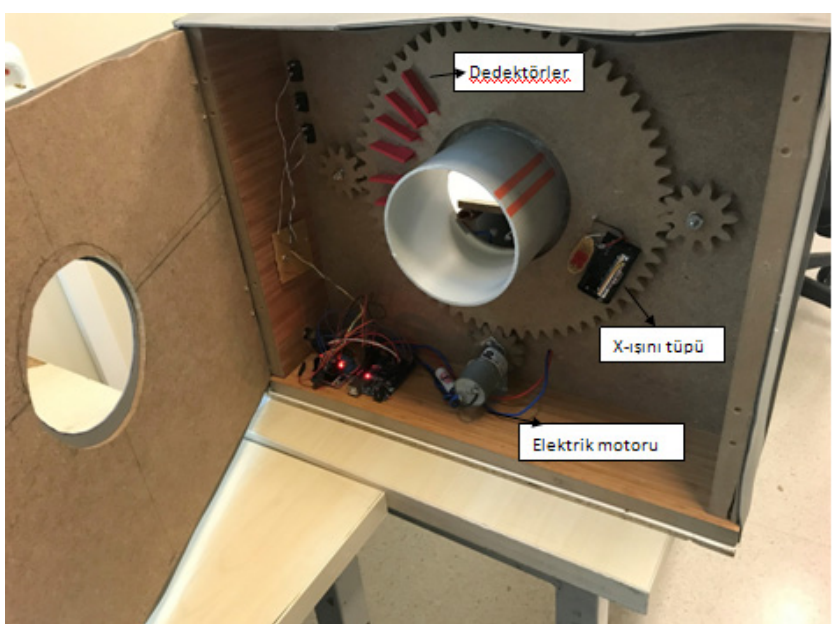

Şekil 4: Bilgisayarlı Tomografi (İç yapısı ve dedektörler)

Mamografi cihazı 3. grup öğrenciler tarafından yapılmıştır. Mamografi (Şekil 5), kompresyon plakası, X-1şını tüpü ve kaset tutucudan meydana gelmiştir. Mamografi cihazında kompresyon plakası ve kaset tutucu hareketli olarak tasarlanmıştır.

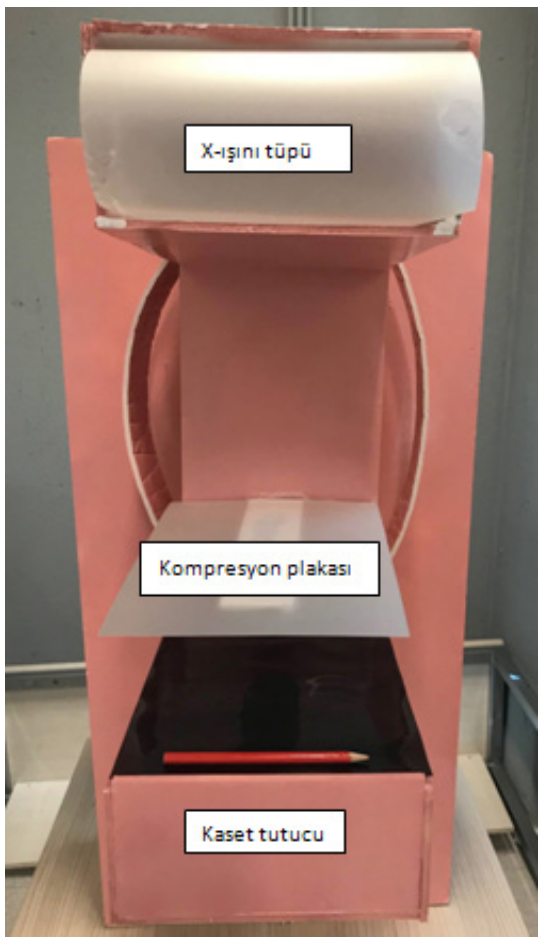

Şekil 5: Mamografi cihazı

Tek foton emisyon bilgisayarlı tomografi cihazı 4. grup öğrenciler tarafından ahşaptan tasarlanmıştır. Cihazdaki, karşılıklı plakalar üzerine gama kameralar yerleştirilmiştir. Hasta yatağı ise oluklu mekanik bir sistem üzerinde hareket edebilmektedir (Şekil 6).

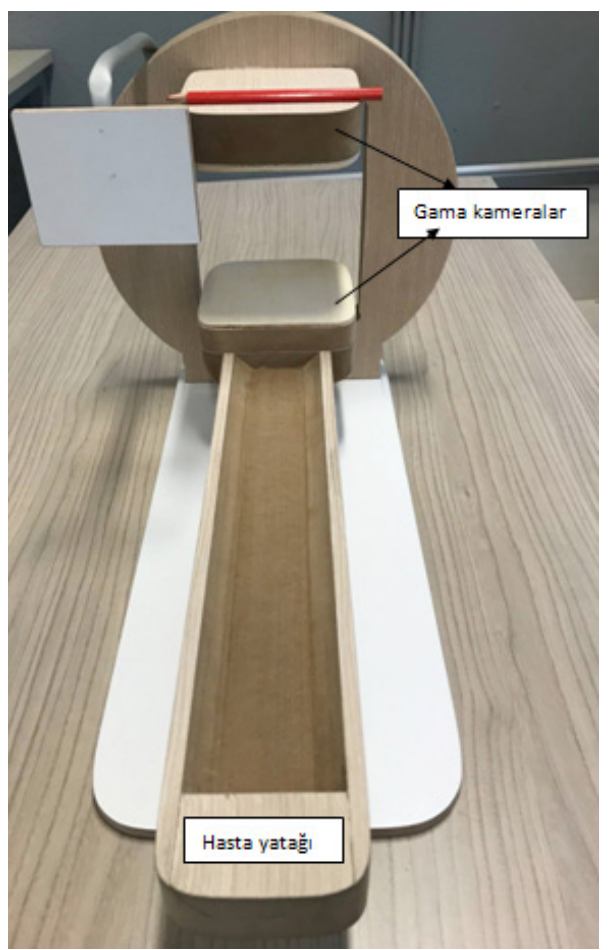

Şekil 6: Tek Foton Emisyon Bilgisayarlı Tomografi (SPECT)

PET cihazı, 5. grup öğrenciler tarafindan kalın mukavva ile dizayn edilmiştir. Dedektörler, gantri boşluğunun çevresine yerleştirilmiştir. Oluk sistemiyle hareketli hasta yatağı oluşturulmuştur (Şekil 7).

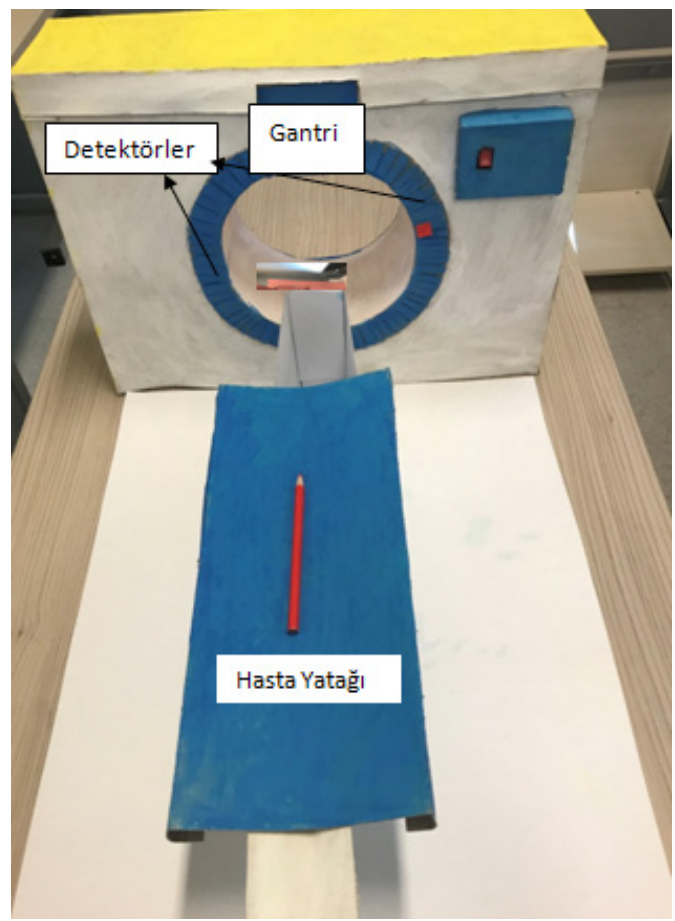

Şekil 7: Pozitron Emisyon Tomografisi 
Proje temelli öğrenmede farklı gruptaki öğrenciler 10 haftalık çalışma sonucunda, tıbbi görüntüleme cihazlarından bir tanesinin tasarlamışlardır ve arkadaşları karşısında sunumlarını yapmışlardır. $\mathrm{Bu}$ kapsamda öğrenciler birbirleriyle uyumlu olarak çalışmışlardır. Çalışma başlangıcından iki hafta sonra çizim üzerindeki projeleri ile çalışma sonunda yaptıkları maketler arasında oldukça büyük fark görülmüştür. Çünkü öğrenciler proje kapsamında tasarladıkları maket çizimlerinin yapımı aşamasında zorlanmışlar fakat karşılaştıkları sorunları aşmak için yeni çözümler üretmişlerdir. Böylece, öğrenciler proje yapımı esnasında birçok problemle karşılaşabileceklerini, bunlar karşında çözüm üretmeleri gerektiğini ve yeni fikir bulmalarını gerektiğini öğrenmişlerdir. Öğrenciler, projelerini hazırlarken, marangozdan, elektrikçiden, danışmanlarından, ailelerinden ve diğer arkadaşlarından yardım almışlarıdır. Yardım aldıkları kişilerden konuyla ilgili birçok yeni bilgi öğrenmişlerdir. Yapılan diğer çalışmalarda, öğrencilerin, proje temelli öğrenme ile problemleri çözebilmedeki yeteneklerinin geliştiği gözlenmiştir (10).
Yapılan tüm maket çalışmaları tamamlandıktan ve sunumlar yapıldıktan sonra, öğrencileri değerlendirilmek amacıyla sözlü sınav yapılmıştır. Sınavda tüm öğrencilere cihazların yapısı ve çalışma prensibi ile ilgili sorular sorulmuştur. Sorular projesi yapılan röntgen, BT, mamografi, PET ve SPECT cihazları ile ilgili olup her cihaz için soru düzeyleri eşit olarak belirlenmiştir. Öğrencilerin sorulara verdikleri cevaplar iki farklı öğretim üyesi tarafından 100 puan üzerinden değerlendirilmiş ve her soru için grup ortalaması alınmıştır. Tablo 1 de her grubun her soru grubuna ait aldıkları puanların ortalamaları ve standart sapmaları verilmiştir. Çalışma sonucunda her grup, modelini kendi yaptıkları cihaz ile ilgili sorulardan, diğer cihazlarla ilgili sorulara göre daha yüksek puan almışlardır. Örneğin, PET cihazı modelini yapan 5. grup, en yüksek puanını (96) PET ile ilgili olan sorulardan almıştır. PET modeline yapan 5. Grup, röntgen ile ilgili sorulardan ortalama 82 puan, BT ile ilgili sorulardan ortalama 72 puan, mamografi ile ilgili sorulardan, ortalama 65 puan ve SPECT ile ilgili sorulardan ortalama 80 puan almıştır.

Tablo 1: Çalışma gruplarının tasarladıkları cihaz ve sınav sonucunda aldıkları ortalama puanlar ve standart sapmalar soru türlerine göre dağılımları (sorular 100 puan üzerinden değerlendirilmiştir)

\begin{tabular}{|c|c|c|c|c|c|c|}
\hline Gruplar & \begin{tabular}{|} 
Tasarladıkları \\
Cihaz
\end{tabular} & $\begin{array}{c}\text { Röntgen ile ilgili } \\
\text { sorulardan alınan } \\
\text { ortalama puan }\end{array}$ & $\begin{array}{l}\text { BT ile ilgili sorulardan } \\
\text { alınan ortalama puan }\end{array}$ & $\begin{array}{c}\text { Mamografi ile ilgili } \\
\text { sorulardan alınan } \\
\text { ortalama puan }\end{array}$ & $\begin{array}{c}\text { SPECT ile ilgili } \\
\text { sorulardan alınan } \\
\text { ortalama puan }\end{array}$ & $\begin{array}{c}\text { PET ile ilgili } \\
\text { sorulardan alınan } \\
\text { ortalama puan }\end{array}$ \\
\hline 1.grup & Röntgen & $97,62 \pm 1,89$ & $90,11 \pm 2,23$ & $86,43 \pm 2,89$ & $74,43 \pm 3,68$ & $67,31 \pm 3,92$ \\
\hline 2.grup & BT & $87,03 \pm 2,58$ & $94,74 \pm 2,11$ & $82,27 \pm 3,91$ & $68,72 \pm 4,21$ & $75,67 \pm 4,38$ \\
\hline 3.grup & Mamografi & $85,26 \pm 4,78$ & $78,07 \pm 5,19$ & $91,76 \pm 1,87$ & $71,24 \pm 3,52$ & $73,34 \pm 3,87$ \\
\hline 4.grup & SPECT & $80,94 \pm 4,12$ & $74,86 \pm 4,73$ & $60,64 \pm 4,29$ & $94,02 \pm 1,74$ & $85,22 \pm 2,56$ \\
\hline 5.grup & PET & $82,37 \pm 3,56$ & $72,28 \pm 4,06$ & $65,19 \pm 3,64$ & $79,67 \pm 3,46$ & $96,13 \pm 1,43$ \\
\hline
\end{tabular}

Yalçın ve arkadaşlarının 2009 yılında yapmış oldukları çalışmada, öğrencilerin projelerine başlamadan önce kolay bir şekilde projeyi tamamlayacaklarını düşündükleri fakat başladıktan sonra birçok kişiden yardım almaları gerektiğinin farkına vardıkları ifade edilmiştir. Bu çalışmada da benzer biçimde öğrenciler elektrikçi ve marangoz gibi birçok kişiden yardım almışlardır (24).

Yapılan çalışmalarda, proje temelli öğrenmede öğrencilerin problem çözme becerisinin geliştiği savunulmuştur. $\mathrm{Bu}$ çalışmada da öğrenciler projelerini yaparken sürekli çevreleriyle etkileşim içerisinde olup, çevrelerindeki bir çok materyali projeye entegre etmeye çalışmışlardır (10,25). Önceki çalışmaların bazılarında, öğrenciler proje yapım sırasında oldukça eğlendikleri söylemişlerdir. $\mathrm{Bu}$ çalışmada da öğrencilerin projelerini zorlanmalarına rağmen eğlenerek yaptıkları gözlemlenmiştir (26-29).

Yapılmış olan birçok çalışmada, proje temelli öğrenim yönteminin öğrenciler üzerinde oldukça fazla olumlu etkisinin olduğu bulunmuştur (30-33). Bu çalışmada proje temelli eğitimin önemli olduğu ve öğrenmede oldukça etkili olduğu sonucuna ulaşılmıştır.

\section{SONUÇ}

$\mathrm{Bu}$ çalışma, iyonize radyasyonla çalışan tıbbi görüntüleme cihazlarının yapısının ve çalışma prensiplerinin proje temelli öğrenilmesi amacıyla yapılmıştır. Bu amaç için, Tıbbi Görüntüleme Teknikleri Programı ikinci sınıf öğrencileri, beş farklı gruba ayrılmıştır. Her grup, röntgen, bilgisayarı tomografi, mamografi, tek foton emisyon bilgisayarli 
tomografi (SPECT) ve pozitron emisyon tomografisi (PET) cihazlarından birini seçmişlerdir. Her grup seçtikleri görüntüleme cihazının yapısı ve çalışma prensipleri ile ilgili çeşitli materyaller kullanarak maket tasarımı yapmışlardır. Çalışma sonunda bütün gruplara cihazlarla ilgili sorulmuş ve öğrencilerin sorulara verdikleri cevaplar değerlendirilmiştir. Öğrenciler, yaptıkları cihazlarla ilgili olan sorulardan, diğer cihazlarla ilgili olan sorulara göre daha başarılı oldukları gözlenmiştir.

$\mathrm{Bu}$ çalışmada proje temelli eğitimin önemli olduğu ve öğrenmede oldukça etkili olduğu sonucuna ulaşılmıştır. Sonuç olarak proje temelli öğrenme, eğitim sisteminin tüm kademelerinde, (anaokulundan üniversiteye) uygulanması önerilebilir. Bu kapsamda yüksek öğretim kurumlarında öğrenim gören öğrencilere, proje temelli eğitim firsatı verilerek, uygulama yapmaları sağlanmalıdır.

\section{KAYNAKLAR}

1. Demir M, Demir B, Sayman H, Sager S, Sabbir Ahmed A, Uslu I. Radiation protection for accompanying person and radiation workers in PET/CT. Radiat Prot Dosimetry. 2011;147:528-532. https://doi.org/10.1093/rpd/ncq497

2. Demir M. Radiobiological Effects, Protection of the Patient, Protection of Caregivers, Protection of Those Around the Patient and the Environment, Nuclear Medicine Seminars 2015;3:171-9, DOI:10.4274/nts.0026

3. Kara U, Kaya A, Tekin HO, Akkurt I. Adult Patient Radiation Doses with Multislice Computed Tomography Exam: MSCT Standard Protocols, Acta Physica Polonica A,2017; 132, 3, 1126-1127,

4. Rezak A, Abbas HM, Ajemian, MS, Dudrick, SJ, Kwasnik EM. Decreased use of computed tomography with a modified clinical scoring system in diagnosis of pediatric acute appendicitis, Archives of Surgery, 2011; 146(1), 64-67,

5. Çelik S. Projeye dayalı öğrenme yaklaşımının fen bilgisi öğretmen adaylarının bilim ve teknolojinin doğası anlayışlarına ve bilimsel süreç becerilerine etkisi. Yayımlanmamış doktora tezi, Atatürk Üniversitesi Fen Bilimleri Enstitüsü, Erzurum,2009.

6. Patton A. Work that matters. The teacher's guide to projectbased learning. Published by the Paul Hamlyn Foundation, 2012.

7. Doppelt Y. Developing pupils' competencies through creative thinking in technological projects. The 28th Israel Conference on Mechanical Engineering, Ben - Gurion University of the Negev Beer-Sheva, Israel, 2000.

8. Doğay G. Ekoloji ünitesinin öğretilmesinde proje tabanlı öğrenme yönteminin öğrenci başarısına etkisi (İstanbul örneği). (Yüksek Lisans Tezi). Gazi Üniversitesi Eğitim Bilimleri Enstitüsü, Ankara, 2010.
9. Dağ F, Durdu L. Öğretmen Adaylarının Proje Tabanlı Öğrenme Sürecine Yönelik Görüşleri. e-Journal of New World Sciences Academy, 2012; 7(1).

10. Korkmaz H. Fen eğitiminde proje tabanlı öğrenme yaklaşımının ilköğretim öğrencilerinin yaratıcı düşünme, problem çözme ve akademik risk alma düzeylerine etkisi. (Doktora Tezi), Hacettepe Üniversitesi, Sosyal Bilimler Enstitüsü, Ankara,2002.

11. Kanter DE, Shreck M. Learning Content Using Complex Data in Project-Based Science: An Example from High School Biology in Urban Classrooms. New Directions For Teaching and Learning, 2006; 108, 77-91.

12. Çelik S, Şenocak Sert A. Proje tabanlı öğrenme yaklaşımının fen bilgisi dersinde öğrencilerin mantıksal düşünme becerilerine ve tutumlarına etkisi. (Yüksek Lisans Tezi), Çukurova Üniversitesi, Sosyal Bilimler Enstitüsü, Adana, 2006.

13. Zeren Özer D, Özkan M. Proje tabanlı öğretimin fen bilgisi öğretmen adaylarının bilimsel süreç becerileri üzerine etkisi. Türk Fen Eğitimi Dergisi, 2012; 9(3), 119-130.

14. Hall EJ, Brenner DJ. Cancer risks from diagnostic radiology, The British Journal of Radiology, 2008; 81(965), 362-378.

15. Mettler Jr FA, Wiest PW, Locken JA, Kelsey CA. CT scanning: patterns of use and dose, Journal of radiological Protection, 2000; 20(4), 353.

16. White KS, Invited article: helical/spiral CT scanning: a pediatric radiology perspective, Pediatric radiology, 1996; 26(1), 5-14

17. Linton OW, Mettler Jr FA, National conference on dose reduction in $\mathrm{CT}$, with an emphasis on pediatric patients. American Journal of Roentgenology,2003; 181(2), 321-329,

18. Brenner DJ, Elliston CD. Estimated radiation risks potentially associated with full-body CT screening, Radiology, 2004; 232:735-8,

19. Bor, D.,Nükleer Tıp Sayısal Görüntüleme Yöntemleri, 2009, Bilim Yayın Evi, Ankara.

20. Cherry SR, Sorenson JA, Phelps ME, Physics in Nuclear Medicine, Saunders Elsevier, ABD, 2012.

21. Bera G, Soret M, Maisonobe J A, Giron A, Garnier J M , Habert MO, Kas A. Equivalent dose rate from patients after whole-body FDG-PET/CT, Médecine Nucléaire, Volume 42, Issue 1, 2018, Pages 45-48, ISSN 0928-1258, https://doi. org/10.1016/j.mednuc.2017.11.003.

22. Quinn B, Holahan B, Aime J, Humm J, St. Germain J, Dauer L. Measured dose rate constant from oncology patients administered $18 \mathrm{~F}$ for positron emission tomography. Medical physics. 2012, 39. 6071-9. 10.1118/1.4749966. DOI: $10.1118 / 1.4749966$

23. Cronin B, Marsden P K, O'Doherty MJ. Are restrictions to behaviour of patients required following fluorine-18 fluorodeoxyglucose positron emission tomographic studies? Eur J Nucl Med. 1999;26:121-128. https://doi.org/10.1007/ s002.590.050367

24. Altun Yalçın, S., Turgut, Ü., \& Büyükkasap, E. Proje Tabanlı Öğretim Yönteminin Öğrencilerin Elektrik Konusu Akademik Başarılarına, Fiziğe Karşı Tutumlarına ve Bilimsel 
İşlem Becerilerine Etkisinin İncelenmesi. International Online Journal ofEducational Sciences,2009; 1(1), 81-105.

25. Frank, M., Lavy, I., \& Elata, D. Implementing the ProjectBased Learning Approach in an Academic Engineering Course. International Journal of Technology and Design Education, 2003; 13, 273-288.

26. Bobroff, J. \& Bouquet, F. A project-based course about outreach in a physics curriculum. European Journal of Physics, 2016; 37, 1-10.

27. Deniş Çeliker, H. Fen ve teknoloji dersi "güneş sistemi ve ötesi: uzay Bilmecesi” ünitesinde proje tabanlı öğrenme Uygulamalarının öğrenci başarılarına, yaratıcı Düşünmelerine, fen ve teknolojiye yönelik tutumlarına Etkisi. 2012; (Doktora Tezi), Dokuz Eylül Üniversitesi, Eğitim Bilimleri Enstitüsü, İzmir.

28. Gültekin, M. Proje tabanlı öğrenmenin beşinci sınıf fen bilgisi dersinde öğrenme ürünlerine etkisi. İlköğretim Online, 2007; $6(1), 93-112$.
29. Mills, P. Group project work with undergraduate veterinary science students. Assessment and Evaluation in Higher Education, 2003; 28(5), 527-538.

30. Dede, Y. ve Yaman, S. Fen ve matematik eğitiminde proje çalışmalarının yeri, önemive değerlendirilmesi. Gazi Üniversitesi Gazi Eğitim Fakültesi Dergisi, 2003; 23(1), 117132.

31. Korkmaz, H., \& Kaptan, F. Fen eğitiminde proje tabanlı öğrenme yaklaşımı.Hacettepe Üniversitesi Eğitim Fakültesi Dergisi, 2001;20, 193-200.

32. Thomas, J. W. A review of research on project-based learning, 2000; http://www.bie.org/index.php/site/RE/pbl_ research/29.

33. Winn S. Learning by doing: Teaching research methods through student participation in a commissioned research project, Studies in Higher Education, 1995; 20(2), 203-214. 